\title{
Age is not just a number - senescence affects how fish populations respond to different fishing regimes
}

Pauliina Anna Ahti ( $\square$ pauliina.a.s.ahti@jyu.fi )

University of Jyväskylä https://orcid.org/0000-0002-6216-9616

\section{Silva Uusi-Heikkilä}

University of Jyväskylä: Jyvaskylan Yliopisto

Timo J Marjomäki

University of Jyväskylä: Jyvaskylan Yliopisto

Anna Kuparinen

University of Jyväskylä: Jyvaskylan Yliopisto

\section{Original Research}

Keywords: senescence, life-history, trade-offs, eco-evolutionary dynamics, body size, fisheries, selection

Posted Date: February 16th, 2021

DOI: https://doi.org/10.21203/rs.3.rs-184938/v1

License: (c) (i) This work is licensed under a Creative Commons Attribution 4.0 International License. Read Full License 
2 Age is not just a number - senescence affects how fish populations respond to different fishing regimes

4 Pauliina A. Ahti ${ }^{1,2^{\star}}$, Silva Uusi-Heikkilä1, Timo J. Marjomäki ${ }^{1}$, Anna Kuparinen $^{1}$

$5{ }^{1}$ Department of Biological and Environmental Sciences, P.O. Box 35, 40014 University

6 of Jyväskylä, Finland

72 Institute of Biodiversity, Animal Health, and Comparative Medicine, College of Medical,

8 Veterinary, and Life Sciences, University of Glasgow, Glasgow, G12 8QQ UK

9 * Corresponding author: Pauliina A. Ahti, Department of Biological and Environmental

10 Sciences, P.O. Box 35, 40014 University of Jyväskylä, Finland, telephone: +358-41-

11 492-4459, e-mail: pauliina.a.s.ahti@jyu.fi

12 Running title: Senescence improves fish population resiliency

13 Keywords: senescence, life-history, trade-offs, eco-evolutionary dynamics, body size,

14 fisheries, selection

15 Total word count: 6800

16 Number of figures: 4

17 Number of tables: 1

18 Appendix 1, Appendix 2, Appendix 3 


\section{Abstract}

22 The presence of senescence in natural populations remains an unsolved problem in

23 biology. Described as an age-dependent increase in natural mortality (known as

24 actuarial senescence) and an age-dependent decrease in fecundity (known as

25 reproductive senescence), the role of senescence in nature is still poorly understood.

26 Based on empirical estimates of reproductive and actuarial senescence, we explored

27 how senescence affects the population dynamics of Coregonus albula, a small,

28 schooling salmonid fish. Using an empirically-based eco-evolutionary model, we

29 investigated how the presence or absence of senescence affects how the fish

30 population responds to pristine, intensive harvest, and recovery phases. Our results

31 showed that at an individual level, the presence of senescence was accompanied by

32 life-history trade-offs, i.e. lower asymptotic length and smaller size and younger age at

33 maturity, both in the presence and absence of fishing. At the population level, the response to different fisheries selection patterns depended on the presence or absence

35 of senescence. Importantly, the results indicate that through the lifehistory trade-offs between early reproduction and late life survival, the young and small individuals can

37 have an important role in population recovery, especially when senescence is present.

Since most life-history and fisheries models ignore senescence, they may be overestimating reproductive capacity and under-estimating natural mortality. Our results highlight the need for increasing biological realism in these models to ensure the successful management of our natural resources. 


\section{Introduction}

Senescence is considered a fundamentally fitness decreasing trait, and its presence and role in natural populations remains an unsolved problem in biology (Monaghan et al. 2008; Selman et al. 2012; Nussey et al. 2013). Senescence is described as agedependent increase in natural mortality (known as actuarial senescence), and agedependent decrease in fecundity (known as reproductive senescence). For much of the $20^{\text {th }}$ century it was thought that very few animals in the wild experience senescence because external factors such as predators, diseases or environmental stressors would kill them before the consequences of aging would commence (Medawar 1952). Today, it is well known that this is not the case and evidence for senescence across taxa is accumulating (Nussey et al. 2013). Several studies of wild populations have shown that trade-offs exist between early and late life performance (Jensen 1996; Bonsall and Mangel 2004; Lemaitre et al. 2014; Maklakov and Chapman 2019), likely contributing to the onset or development of senescence in an individual. The early vs. late life performance has been tested in many vertebrates and has gained a lot of support, but tests in fishes are scarce, mainly owing to the difficulty of testing for senescence in species with indeterminate growth (Heino and Kaitala 1999; Reznick et al. 2002; Lemaître et al. 2015).

Life-history trade-offs may take place between functions as well as within the same function. For instance, increased growth rate and increased reproductive effort early in life and higher natural mortality rate later in life are known to be linked (Kirkwood and Rose 1991; Lester et al. 2004). Similarly, investment in future reproductive effort is thought to be of lesser value in terms of fitness benefits than current reproductive effort, 
67 mainly due to the uncertainty of future reproduction (Zhang and Hood 2016). Following the close link between life history characters and senescence, it is therefore likely, as hypothesised by Benoît et al. (2018), that assuming that increased allocation to reproduction in early life leads to an increased rate of ageing later, fishing-induced changes in maturation age and senescence could actually be linked. Indeed, the natural

72 mortality rate of many fish populations is thought to have increased in the recent 73 decades (Gislason et al. 2010).

74 While most fishes express indeterminate growth and high longevity (Carey and Judge,

75

76

77

78

79

80

81

2000), it has been suggested that fish experience delayed senescence relative to birds and mammals, facilitated in part by the capacity for increasing fecundity with age (Reznick et al. 2002). Indeed, female body size and reproductive output in fish are known to be positively correlated, indicating that the older and larger the fish, the higher its reproductive output. Most fisheries and fish population models (Beverton-Holt, 1957; Enberg et al., 2010; Andersen and Beyer, 2015; Zimmermann and Jørgensen, 2015) and life-history models (Roff, 1983; Brunel et al., 2013; Charnov et al., 2013) assume that body size (weight) scales isometrically with reproductive output. Recent metaanalysis has provided cues that the scaling might even be hyper-allometric in some cases (Barneche et al. 2018), further stressing the role of large and old individuals for population growth or, in case of over-exploitation, for recovery. Additionally, in fisheries and life-history models, the natural mortality of fish is often assumed to be independent of the age or size of the fish (Gislason et al. 2010). Models with increasing fecundity with age and size, and age- and size-independent natural mortality essentially describe fish as having no reproductive or actuarial senescence at all. 
While rarely included in fisheries and life-history models, senescence in fish was first

91 documented over 60 years ago (Gerking 1957; Comfort 1960, 1963; Woodhead and

92 Ellett 1966, 1967, 1969a, b). Over the past few decades, evidence for both reproductive

93 (Reznick et al. 2006; Benoît et al. 2018) and actuarial (Beverton et al. 2004; Uriarte et

al. 2016) senescence as well as general deterioration with age (Patnaik et al. 1994; Hendry et al. 2004; Morbey et al. 2005; Carlson et al. 2007) in fish has started to accumulate. While the importance of old and large individuals for the reproductive pool is evident, the common conservation measure of relying on the reproductive effort of large individuals could have detrimental effects on the recovery and resilience of fish populations if actuarial or reproductive senescence is indeed wide-spread in fishes (Le Bris et al. 2015). Given that senescence influences the reproductive outcome and natural mortality rate, it would also have major consequences to our understanding of fish population dynamics and would thereby affect our management efforts of fish populations.

Sustainable fish populations are vital not only for food security around the world (Merino et al. 2012), but also for healthy biodiversity and climate regulation (Jackson 2008). Several fish populations that have collapsed as a result of fishing, have not recovered or are recovering slower than expected even after significant declines in fishing effort (Hutchings and Reynolds 2004). The reasons behind the lack of recovery are complex and likely include factors such as habitat destruction, climatic conditions, trends in preypredator relationships, and changes in life-history traits (Dulvy et al. 2003a; Hutchings and Reynolds 2004; Olsen et al. 2009). While much research effort has been put into understanding the links between life-history traits such as body size, growth rate, size 
113 and age at maturity, and population dynamics (Ahti et al. 2020), the role of reproductive 114 and actuarial senescence in population dynamics and population recovery remains 115 poorly understood.

116 Monitoring and measuring reproductive or actuarial senescence in nature is notoriously 117 difficult, particularly for fish, and the fishes with the most data tend to be the fishes that 118 are the most heavily fished, therefore likely caught before senescence commences.

119 Here, we used empirical data to parameterise an existing eco-evolutionary model 120 (Kuparinen et al. 2011) to overcome these obstacles and to illuminate the role of 121 senescence in fish population dynamics and population recovery under two different 122 fishery selection schemes. As opposed to experimental or empirical studies, the 123 simulation model allows us to control the presence and absence of senescence and 124 explore how, all else being equal, it influences fish population dynamics in the presence 125 and absence of fishing. We used vendace (Coregonus albula, Linnaeus), an

126 economically and culturally important freshwater salmonid, as a model species.

127 Specifically, we address the following questions: 1) How does the presence or absence 128 of senescence influence the population dynamics of fish, in terms of biomass and 129 number of fish prior to fishing? And 2) how does the response to different fishery 130 selection schemes differ depending on the presence or absence of senescence? Our 131 results provide insights into the effects of senescence on population dynamics before, 132 during, and after harvest, and how including it in fisheries and life-history models may 133 improve our understanding of population dynamics and facilitate management efforts.

\section{Materials and methods}


135 To explore the role of senescence in Coregonus Albula (Linnaeus) life-histories and populations, we used an individual-based model that incorporates empirical growth,

137 fecundity, and survival data with the principles of quantitative genetics and demographic 138 processes. The core of this mechanistic model lies in the strong negative correlations 139 among the von Bertalanffy $(\mathrm{vB})$ growth model parametres $L_{\infty}$ (asymptotic length), and $k$ 140 (intrinsic growth coefficient, i.e. how fast the fish length is approaching $L_{\infty}$ ) and the size 141 at maturity (von Bertalanffy 1938, 1949; Quince et al. 2008). Since the simulation model 142 has been described in detail elsewhere (Kuparinen et al. 2011), we will here limit the 143 model description to a general description of the modelling approach and the main 144 features and additions specific to our study design. While the empirical data are from 145 Lake Puulavesi in Central Finland, the results can be generalised to any fish with similar 146 life-history properties.

\section{General description of the modelling approach}

148 The eco-evolutionary model includes five main components (Fig 1a - e). These are four 149 dependent sets of variables: growth, fecundity, survival, population demographics, and 150 an independent variable: senescence.

151 Life history traits such as size and age at maturity are thought to be controlled by many 152 loci (Roff 2002). In fishes, the correlation of size at maturity and $L_{\infty}$ is a well-known life153 history invariant (Charnov 1993). Thus, in the growth component (Fig. 1a), we utilised 154 empirical length-at-age data back-calculated from fish scales to model the $L_{\infty}$. The $L_{\infty}$ 155 was set to be an evolving trait so that the genotype coding $L_{\infty}$ of each individual was 156 described by 10 diploid loci with two alleles in each. The alleles were inherited in the 157 classic Mendelian way, so that each offspring received one randomly drawn allele from 
158 the mother, and one from the father. Each allele was coded as 0 or 1 and the sum of 159 alleles across the ten loci was coupled with a normally distributed random number 160 (mean zero) to describe phenotypic variability, and then the sum was linearly translated 161 to values of $L_{\infty}$. The standard deviation of the normally distributed random number was 162 adjusted to yield a realistic heritability of 0.2-0.3 (Mousseau and Roff 1987). The vB 163 growth parameter $\mathrm{k}$ and the size at maturity were then determined based on $L_{\infty}$. (For 164 more on k see below "Model parametrisation"). We used the empirical data to determine 165 that the maturation size threshold was at $67 \%$ of their $L_{\infty}$ (mean size at 2 years of age) 166 and no earlier than on their second autumn, which is in line with literature (Jensen 167 1998; Karjalainen et al. 2016). This way, we ensured that the fish in the model will 168 mature once they reach $67 \%$ of their $L_{\infty}$, but never before they reach their second 169 autumn. Thus, fish younger than two years old, or two-year-olds smaller than $67 \%$ of 170 their $L_{\infty}$ could not yet reproduce.

171 The fecundity component (Fig. 1b) is based on a length-weight relationship, which was 172 specifically calculated for $C$. albula from Lake Puulavesi. Using this length-weight 173 relationship and published empirical data on egg numbers and female weights 174 (Karjalainen et al. 2016), we fitted a linear model for the fecundity-weight relationship.

175 The survival component (Fig. 1c) includes an empirically based (Marjomäki et al. 2014; 176 Karjalainen et al. 2016) probability $(P=0.002)$ for a fertilized egg to hatch and the 177 juvenile to survive until 2 years of age. The sex of the juveniles was drawn from a 178 Bernoulli trial with a probability of 0.5 . Mating occurred randomly, so that for each 179 mature female a random mate was drawn from a group of mature males. The maximum 
180 lifetime for each individual was limited to 6 years, according to local estimations in Lake 181 Puulavesi (Marjomäki and Huolila 1994).

182 The population component (Fig. 1d) describes density dependency so that at $75 \%$ of 183 the population carrying capacity, the individual growth is reduced to $50 \%$ of that 184 predicted by the individual's vB growth curve (its $L_{\infty}$ and k parameters). Additionally, egg 185 186 production was set to be density dependent so that the closer the population was to its carrying capacity, the fewer eggs were produced.

187 The fifth component of the eco-evolutionary model describes senescence in its two 188 forms: reproductive senescence and actuarial senescence (Fig. 1e). The reproductive 189 senescence was modelled by multiplying the linear model for fecundity by the 190 gonadosomatic index (GSI) for the year class in question. When no reproductive 191 senescence was modelled, only the linear model for fecundity was used. Actuarial 192 senescence was modelled by increasing the rate of natural mortality each year, as 193 opposed to keeping natural mortality rate constant throughout lifetime as in the scenario 194 with no actuarial senescence. All the other components were kept identical in the 195 simulations (Fig. 1f), but the presence and absence of reproductive and actuarial 196 senescence was altered.

197 Each population in each scenario was then allowed to "live" for 500 years, and the 198 individuals and populations were traced at annual time steps. At each annual step, the 199 growth, reproduction, and mortality of each individual fish was simulated to get the 200 population data for the next year. During those 500 years, the populations experienced 201 three consecutive phases: 200 years of pristine phase, 100 years of intense fishing, and 202200 years of recovery (Fig. 1f). The output data of particular interest, i.e. asymptotic 
203 length $\left(L_{\infty}\right)$, biomass $(\mathrm{BM})$, and number of fish $(\mathrm{N})$ was collected annually. Each

204 simulation was replicated 100 times.

\section{Parametrisation of the model}

206 The empirical data were collected from Lake Puulavesi, an oligotrophic lake located in 207 Central Finland. Its areal coverage is approximately $330 \mathrm{~km}^{2}$, with an average depth of $2089.2 \mathrm{~m}$ and the deepest part reaching $62 \mathrm{~m}$. The samples for vendace age and growth 209 determination were collected from different basins of Lake Puulavesi between 1977 and 210 2017. The model is based on empirically observed growth trajectories (total $\mathrm{N}=93$,

211 female $N=62$, male $N=31$ ). The age was determined from the annuli of vendace 212 scales located below pelvic fins. The radius of the entire scale (S) and the radius from 213 scale focus to the annulus $\mathrm{i}\left(\mathrm{S}_{\mathrm{i}}\right)$ were measured from the anterior part of the scale that 214 was magnified (20-40 x) using a microfiche reader. The ages were as follows: 3 -year215 olds $\mathrm{N}=34 ;$ 4-year-olds $\mathrm{N}=20 ; 5$-year-olds $\mathrm{N}=37$; and 6-year-olds $\mathrm{N}=2$. Because 216 the length at age was back-calculated, the older the fish, the more information it 217 provided from the previous years. Vendace is known to reach maturity usually on their 218 second autumn, so it was here assumed that all the specimens were mature. The back219 calculation of length at age $\left(L_{t}\right)$ of each individual was done using the Monastyrky's 220 equation $L_{t}=L \times\left(\frac{s_{t}}{s}\right)^{b}$ (Monastyrsky 1930), where $L=$ the measured total length when 221 the fish was caught, $S_{t}=$ the width of annulus at age $t, S=$ radius of the entire scale, 222 and $b=0.641$. The value of 0.641 for the exponent $b$ is an estimate from several 223 Finnish vendace stocks (Marjomäki and Huolila 2001). 
224 The empirically collected weight data $(\mathrm{N}=27)$ and the growth trajectories calculated

225 above were used to calculate the length-weight relationship $W=a \times L^{b}$ (Ricker 1975).

226 In this equation $\mathrm{W}=$ fresh weight in grams (precision $0.1 \mathrm{~g}$ ) and $\mathrm{L}=$ length in $\mathrm{cm}$

227 (precision $1 \mathrm{~mm}$ ). The parameter a (scaling coefficient for the weight at length of the

228 fish) the parameter $b$ (shape parameter for the body form of the species) were

229 calculated to be $a=0.007$, and $b=0.003$. The lengths varied between 120 and $170 \mathrm{~mm}$

230 (mean $146 \mathrm{~mm}$, s.d. = 8.63), and the weights varied between 12 and $27 \mathrm{~g}$, (mean 18.7

231 g, s.d. = 3.7). The length - weight relationship is important because weight scales with

232 fecundity, and therefore plays a crucial role in population dynamics. In this particular

233 study, it also forms the basis that reproductive senescence is modelled on.

234 Back-calculated individual growth trajectories from Lake Puulavesi were summarised

235 using a non-linear least-squares fit of the vB growth equation which was fit for our data

$236 L_{t}=L_{\infty}-\left(L_{\infty}-L_{0}\right) e^{-k t}$, where $L_{t}=$ length at age t, $L_{\infty}=$ asymptotic length, $L_{0}=$ length

237 at $t=0$, and $k=$ the intrinsic individual growth rate. The association between the $v B$

238 parameters $L_{\infty}$ and $\mathrm{k}$ was estimated using an empirically based linear regression model

239 which yielded the following fit: $\ln (\mathrm{k})=1.27-0.13^{*} L_{\infty}$ with residual s.d. $=0.30$.

240 In the scenarios with no reproductive senescence (i.e. how most life-history and

241 fisheries models describe reproduction), fecundity was based purely on the linear

242 function for individual fecundity per gram body weight: $39.06+118.47 \times$ wet mass in

243 grams (Table 1) derived from empirical data (Karjalainen et al. 2016). For ease of

244 comparison against the reproductive senescent scenario, we assigned a "fecundity

245 factor" of 1 for each age group, meaning no change in fecundity with age (Table 1). 
246 Karjalainen et al. (2016) showed an age-dependent decrease in gonadosomatic index

247 (GSI), a pattern that could be indicative of reproductive senescence. We used this GSI as a proxy for reproductive senescence (Table 1). As we only had GSI data for fish up

249 to four years old, the GSI for 5- and 6-year-old fish was linearly extrapolated from the

250 existing data. We used linear extrapolation, because we are interested in the

251 mechanistic changes in population, and not specifically only in vendace. Instead of

252 using the absolute GSI values to describe reproductive senescence in the model, we

253 standardised the effect of reproductive senescence so that the GSI for age group 1 was

254 set to be the baseline and have a fecundity factor of 1 (i.e. no change, same as the non-

255 senescent population), and the following age groups from 2 to 6 were assigned a

256 fecundity factor proportional to that of age group 1 . The fecundity factor was calculated

257 by dividing the GSI of age group 1 by the GSI of the age group in question, so for

258 instance to get the fecundity factor for age group 4 would be as follows: GSI for age

259 group 1/ GSI for age group 4. The linear function for fecundity (described above) was

260 then multiplied by the appropriate fecundity factor for each age group (Table 1) to model

261 reproductive senescence. This way, as the fish ages, its reproductive output declines

262 with age.

263 When actuarial senescence was not modelled, the natural mortality rate was coded to

264 be an age-independent constant of $M=0.257$ in all adult age groups (Table 1 ).

265 To model actuarial senescence, we coded a natural mortality rate $(M)$ that increases

266 with age. The senescence scenario was modelled so that a baseline natural mortality of

$267 M=0.2$ was set for 2 year olds, and the added mortality rate per each age group was

268 adjusted to proportion from Marjomäki (2005) and is shown in Table 1. The difference 
269 between natural mortality imposed by actuarial senescence and fishing mortality is that

270 natural mortality as a result of actuarial senescence increases with age, while the

271 fishing mortality is size-dependent.

272 To allow for a careful investigation of the resulting demographic structures, the actual

273 resulting natural mortality at the population level was scaled to be identical in all

274 scenarios. This means that the total natural mortality over time in all scenarios is the

275 same, but for populations with no actuarial senescence the mortality rate was

276 unchanged over age classes, and for the populations with actuarial senescence

277 present, the mortality increased with age. So, whether the natural mortality remained

278 unchanged over age classes or increased with age, the total natural mortality for a

279 population over time was equal, only the distribution among age classes differed.

280 An increase in natural mortality following sexual maturity and reproduction is an

281 important trade-off in life-history evolution (Kuparinen et al. 2011). To take this into

282 account, and to add biological realism in the model, a survival cost of reproduction i.e.

283 increased mortality rate after having become sexually mature was added to the natural

284 mortality rate in every scenario, for every maturing fish. The survival cost of

285 reproduction was estimated to be the increase in mortality rate from age group 1 to age

286 group 2 as per Marjomäki (2005), and this was applied once in every scenario, whether

287 actuarial or reproductive senescence was modelled or not.

288 Simulation design

289 The initial starting population was 2000 individuals. The population size was selected 290 due to model optimisation and plays no role in the results of the study. Each scenario 
291 was then simulated for 1000 years. All populations reached a state of ecological stability

292 in approximately 600 years. One hundred ecologically and evolutionarily stable

293 populations were saved for all scenarios, and these populations were then randomly

294 sampled to be used as the starting population in further simulations.

295 Simulations were run for 500 years. The population was kept in a pristine equilibrium

296 state for 200 years before fishing was simulated for a period of 100 years. Fishing

297 started in year 200 and ceased in year 300, and populations were then allowed to

298 recover for 200 years. Vendace is traditionally fished by seining and trawling, which

299 means that the retention probability increases with the size of the fish to a certain size

300 and is constant after that. To mimic seining or trawling selection and to describe length-

301 dependent gear selectivity in the population, we used a logistic curve $r(l)=$

$302\left(\frac{\exp (a+b l)}{1+\exp (a+b l)}\right)$, where $r(I)=$ the retention probability of a fish of length $I$, and $a=-9$ and

$303 b=0.85$ are shape parameters, so that $50 \%$ retention probability is reached at length -

$304 \mathrm{a} / \mathrm{b}$ (Kuparinen et al. 2009). We also ran separate simulations for gill net fishing by

305 describing a dome-shaped selectivity curve $r(l) \sim \exp \left(-\frac{(l-\mu)^{2}}{2 \sigma}\right)$, where $r(I)=$ the

306 retention probability of a fish of length $I, \mu=12$ (fish length in $\mathrm{cm}$ at which the selection

307 curve peaks), and $\sigma=0.5$ (standard deviation describing the width of the curve around

308 its peak). For simplicity hereafter, when we discuss trawling, a logistic selection curve is

309 assumed, and when we discuss gillnetting, a dome-shaped selection curve is assumed.

310 Regardless of the fishing method, the fishing mortality $(F)$ of the fully selected size class

311 was set to 0.7 , which is considered a realistic level of magnitude for intensively fished

312 populations (Viljanen 1986). The fishing mortality in terms of biomass was kept identical 
313 for the senescent and non-senescent scenarios. All scenarios were explored across

314 pristine, harvest and recovery periods over 500 years. We created 100 independent

315 replicates for each scenario.

316 All simulations and analyses were conducted using $R$ version 1.1.456 (R Core Team, 317 2018).

\section{Results}

319 Populations in all scenarios had reached an equilibrium and therefore showed only

320 minor temporal fluctuations in any of the population parameters before fishing

321 commenced in year 200. However, scenarios including actuarial senescence

322 consistently differed from those that did not include actuarial senescence. These

323 differences were seen before, during and after fishing in all parameters investigated.

324 Given that actuarial senescence appeared to be the major cause of the differences (Fig.

325 2), likely due to the relatively low reduction in reproductive output with age (Fig. S1, S2),

326 we focus most of the present work on two instead of four scenarios: a scenario with

327 both reproductive and actuarial senescence and a scenario with no senescence.

328 Additionally, reproductive and actuarial senescence are known to be linked (Kirkwood

329 and Shanley 2010), so exploring either both types of senescence together or none at all

330 is biologically more relevant than separating the senescence types.

331 Asymptotic length

332 The populations with senescence had a consistently lower $L_{\infty}$ than those with no

333 senescence. For both the senescent and non-senescent scenarios, fishing caused a

334 decline in $L_{\infty}$ (Fig. 3a, b), and the decline caused by trawling was larger than the decline 
335 caused by gillnetting, regardless of the presence of senescence. However, the type of 336 fishing played a role in the relative change within a scenario. The senescent scenario had 337 a smaller decline in $L_{\infty}$ than the non-senescent scenario when trawled (Fig. 4a). The opposite occurred when gillnetting was applied: the senescent scenario had a larger drop in $L_{\infty}$ as a result of dome-shaped fishing compared to the non-senescent scenario (Fig. 4b). When fishing was ceased after 100 years, $L_{\infty}$ started to increase slowly in all scenarios, but in none of the scenarios did the $L_{\infty}$ recover back to the level prior to fishing.

342 Associated changes in the vB growth parameter $k$, and average size and age at 343 maturation are shown in supplementary material (Fig S3 a, b, c, d, respectively).

Biomass

345 In the absence of fishing, whether pristine or recovery phase, the scenario with senescence produced a lower biomass than the scenario without senescence (Fig. 3c,

347 d). When fishing pressure was applied the biomass of both populations declined.

348 Trawling (Fig. 3c) caused a larger drop than gillnetting (Fig. 3d). However, when

349 trawled, the population with senescence maintained a higher biomass than the one 350 without senescence (Fig. 3c). In the gillnetting scenario, the senescent population had a 351 slightly lower biomass during fishing compared to the non-senescent population (Fig. $3523 d)$.

353 Regardless of the type of fishing, the relative drop in biomass for populations with 354 senescence was smaller than for those with no senescence (Fig. 4 c, d). When trawling 355 was applied, the level of biomass stayed relatively constant for both senescent and non356 senescent scenarios (Fig. 4c). However, gillnetting caused a sharp decline in biomass 357 then a sharp increase and then a slow, continuous decline for both scenarios (Fig. 4d). 
358 The decline did not level off at any point during hundred years of fishing. When fishing

359 was ceased, all scenarios experienced a rapid increase in biomass with an initial peak

360 (that exceeded the level prior to fishing in gillnetting scenario), and then a sharp drop.

361 These peaks and drops were larger in the gillnetting scenario compared to the trawling

362 scenario. While all scenarios eventually settled to little variation and a slow, increasing

363 trend, in two hundred years of recovery, no population had recovered to the pre-fishing

364 levels.

\section{$365 \quad$ Number of fish}

366 The number of individuals $(M)$ was consistently higher for populations with senescence, 367 than for those without, regardless of fishing type or the presence or absence of fishing 368 (Fig. 3e, f). The start of trawling caused a rapid initial decline in the number of fish, but 369 as trawling continued, the $N$ increased in both senescent and non-senescent scenarios, 370 however it never reached the pre-fishing level (Fig. 3e). This was different from

371 gillnetting, which caused a steady increase in the $N$ during fishing, above the pre-fishing

372 levels (Fig. 3f). As fishing was ceased, the populations that were trawled experienced a

373 rapid initial increase in $N$, and then a declining trend. When gillnetting was ceased, it 374 caused a slow decline in the number of fish. No scenario reached the pre-fishing level in 375 two hundred years of recovery.

376 In both trawling and gillnetting scenarios, the relative change in the number of fish was

377 smaller for the senescent scenario, compared to the non-senescent scenario (Fig. 4e, 378 f). However, as the fishing continued, the difference between the senescent and non379 senescent scenarios declined. 


\section{Discussion}

381 Many collapsed fish populations have not recovered even after significant reductions in

382 fishing pressure, or are recovering slower than expected (Hutchings and Reynolds

383 2004). Our individual-based eco-evolutionary simulations shed light on how

384 reproductive and actuarial senescence affect fish population dynamics under different

385 fishing selection regimes. Populations with senescence evolved to have a lower $L_{\infty}$, and

386 during fishing the $L_{\infty}$ declined further. However, the senescent and non-senescent

387 populations responded differently to different fishing selection regimes: when fishing by

388 trawling (described by a logistic selection curve), the relative decline in $L_{\infty}$ in the

389 senescent population was less than in the non-senescent population. When fishing by

390 gillnet (described by a dome-shaped selection regime), the opposite occurred, and the

391 senescent population experienced a proportionately larger decline in $L_{\infty}$. The effect of

392 senescence on population dynamics in terms of biomass and number of fish appeared

393 to be density dependent. When the population was relaxed from strong density

394 dependency during trawling, populations with senescence maintained a higher biomass

395 and had a higher $\mathrm{N}$ than populations with no senescence present. When gillnetting was

396 applied, the senescent population maintained higher numbers, but the total biomass

397 was lower than the non-senescent population's biomass. Given the sensitivity of

398 fisheries models to the mass-fecundity relationship and total mortality rates, and the

399 common practice of relying on the reproductive effort of old, large individuals, these

400 results draw attention to the importance of considering senescence as a life-history trait

401 affecting population dynamics and recovery.

402 Asymptotic length 
403 Populations experiencing senescence evolved to have smaller asymptotic length and 404 coupled with this was a higher intrinsic growth rate, and smaller size and younger age at 405 maturation. These trends were present both when there was no fishing and therefore 406 density-dependent processes regulated the population size, and when fishing had 407 relaxed the population from strong density-dependent competition. Both extrinsic 408 mortality (fishing) and intrinsic mortality (actuarial senescence) led to a declining 409 asymptotic length. This may indicate the presence of a trade-off between increased 410 investment in growth and/ or reproduction early in life (as asymptotic length was 411 associated with earlier reproduction and higher growth rate) and decreased survival 412 later in life. The well-known effects of fishing-induced evolution i.e. selection toward 413 smaller size, smaller size at maturation, and higher growth rate (Heino et al. 2015; 414 Hunter et al. 2015; Uusi-Heikkilä et al. 2015) may therefore enhance the trade-offs 415 associated with senescence and the evolution of life-history traits. Additionally, if 416 increased allocation of resources to reproduction early in life is associated with 417 decreased survival later in life (Kirkwood and Rose 1991), fishing-induced evolution 418 may be indirectly promoting the evolution of senescence through selecting for smaller 419 size and age at maturity.

420 An interesting effect was seen in the response of senescent and non-senescent fish to 421 different fishing methods when comparing the pristine, fishing, and recovery phases 422 within scenarios. Trawling caused a larger absolute decline in asymptotic length (Fig. 423 3a) than did gillnetting (Fig. 3b) for both senescent and non-senescent populations. 424 However, in the trawling scenario the asymptotic length of the senescent population 425 declined proportionately less than that of the non-senescent population (Fig. 4a). The 
426 opposite occurred in the gillnetting scenario (Fig. 4b), where the asymptotic length of

427 the senescent population declined proportionately more from the pristine phase to the

428 fishing phase compared to the non-senescent population. In the 200 years of recovery,

429 the recovery rates of asymptotic length in senescent and non-senescent populations

430 also varied. The different response of senescent and non-senescent fish to different

431 fishing methods is an important notion, as the presence or absence of senescence can

432 affect the magnitude of the change in lifehistory traits in response to fishing. Further, the

433 change in lifehistory characters directly and indirectly affects the population level

434 response.

435 Population level consequences of senescence

436 The changes in asymptotic length, and associated changes in growth rate, and size and

437 age at maturity translated to changes in population level variables. As the carrying

438 capacity of both senescent and non-senescent populations were the same, and the

439 asymptotic length of the fish decreased as a result of senescence and/ or fishing, the

440 senescent population could contain a higher number of fish through pristine, fishing and

441 recovery phases. However, the response of the senescent and non-senescent

442 populations in terms of biomass differed during fishing, and the type of fishing affected

443 the response.

444 In absolute terms, the senescent population maintained a higher biomass during

445 trawling than the non-senescent population (Fig. 3c). Our simulation allowed for control

446 over the fishing mortality, and the catch in terms of biomass was set identical for the

447 senescent and non-senescent populations. Before the fishing started, the population

448 with senescence had a lower biomass than that of the non-senescent population. Since 
449 the absolute biomass of the catch is the same in both populations, this means that the 450 proportional catch from the senescent population (with initially lower biomass) is higher

451 than the catch from the non-senescent population (which had a higher biomass initially).

452 Therefore, the lower asymptotic length of the senescent population (Fig. 3a) did not lead

453 to them being less likely to get caught, but indeed the opposite. Regardless of being 454 more likely to get caught, the senescent population maintained a higher number and 455 higher biomass than the non-senescent population. The explanation for the higher 456 biomass and the higher number of senescent population compared to the non-

457 senescent population is likely in the lifehistory trade-offs. The population with 458 senescence has evolved to have a lower asymptotic length and therefore they mature 459 and start reproducing younger and at a smaller size. Fishing as a source of external 460 mortality pushes the age and size at maturity even younger and smaller, so the higher 461 biomass and number of fish is likely maintained by this earlier reproduction and not 462 lesser fishing mortality. This is an important notion, as management practices tend to 463 focus on saving the big fish (Birkeland and Dayton 2005; Barneche et al. 2018). While 464 we do not deny the importance of big fish, we wish to draw attention to the important 465 contribution that smaller fish can have in population recovery, especially in extensively 466 exploited populations.

467 Gillnetting presents a different kind of selection curve than trawling. While the logistic 468 selection curve of trawling allows virtually no escapement of the larger fishes, the dome469 shaped selection curve of gillnetting selects the mid-sized and allows the escapement of 470 small and large fish. This kind of selection curve leads to a less skewed population in 471 terms of size, and consequently age. As a result, the responses of senescent population 
472 and the non-senescent population to gillnetting in terms of biomass did not differ as

473 much as they did to trawling. However, the drop in biomass from pristine phase to

474 fishing phase was relatively smaller for the senescent population (Fig. 4d), despite the

475 larger relative drop in asymptotic length (Fig. 4b). Like the situation in trawling scenario,

476 the enhanced reproduction of younger and smaller fish is likely to drive the relatively

477 higher biomass of the senescent population.

478 The present study showed a decline in the age and size at maturity for senescent

479 populations, and fishing enhanced this trend further. However, the changes (or the

480 direction of the change) in life-history traits as a result of fishing depend on many factors

481 including species, fishing effort, and environmental conditions. In their meta-analysis,

482 Rochet (1998) controlled for the effect of phylogeny and showed on 77 stocks that

483 fishing induced a decline in age at maturity but an increase in size at maturity. If this

484 were to occur in addition to senescence, it could be speculated that this would likely

485 lead to similar results than in the present study: younger age but larger size at

486 reproduction would probably mean that the reproductive output is even higher if

487 fecundity is assumed to scale isometrically with body size, as most lifehistory and

488 fisheries models do, thereby highlighting the role of young individuals in population

489 recovery even more. However, the increased density of young fish may eventually lead

490 to higher density dependent mortality at younger age classes, or decline in food

491 availability, which could indirectly affect recruitment (Abrams and Rowe 1996). More

492 studies are needed to understand the recruitment dynamics under different density

493 scenarios. 
494 While the asymptotic length of senescent and non-senescent fish responds to different 495 fishing selection regimes differently, the population level consequences of senescence 496 might be partially density dependent (Graves and Mueller 1993). During high external 497 mortality it might be better to invest in reproduction rather than grow large. In other 498 words, given that senescent fish are smaller to start with, senescence may buffer the 499 population against high external mortality by pushing for earlier reproduction. Indeed, 500 looking at the other side of the coin, high rate of external mortality is expected to 501 accelerate the rate of senescence (Williams 1957) and as a trade-off potentially select 502 for earlier reproduction.

503 The density-dependent consequences of senescence can be seen when the effects of 504 reproductive and actuarial senescence are teased apart (Fig. 2). While the populations 505 with actuarial and reproductive senescence have lower asymptotic length before fishing 506 pressure is applied, under fishing pressure this population maintains higher asymptotic 507 length than a population with actuarial senescence only. This suggests that during high 508 external mortality, if the population experiences both types of senescence (actuarial and 509 reproductive), then maintaining a larger body size becomes beneficial in order to 510 maximise fitness in terms of producing as many offspring as possible. On the other

511 hand, for a population with only actuarial senescence, their reproduction does not suffer

512 in terms of declining GSI with age, so therefore smaller body size carries smaller fitness

513 penalty compared to populations that experience both types of senescence.

514 Implications to fisheries science

515 Exploitation and over-exploitation are major causes for the decline of fisheries (Perissi 516 et al. 2017) and even extinction of fish populations (Dulvy et al. 2003b). The traditional 
517 density-dependent population growth theory suggests that at low abundance

518 populations should grow at a fast rate. Following this, fish stocks should recover quickly

519 after fishing has been ceased. Yet, despite large-scale fishing moratoriums, many fish

520 stocks have not fully recovered from intense fishing and remain low (Myers and

521 Barrowman 1997; Bailey 2011; Rougier et al. 2012; Pedersen et al. 2017), or are

522 recovering at a lower rate than expected (Hutchings and Reynolds 2004). While the

523 reasons behind the lack of recovery are complex, the failure of fishing moratoriums to

524 result in stock recovery warrants a closer investigation at the life-history evolution and

525 trade-off in fish, and the potential demographic consequences thereof.

526 Based on the evidence for the presence of senescence in fish (Gerking 1957; Comfort

527 1960, 1963; Woodhead and Ellett 1966, 1967, 1969a, b; Patnaik et al. 1994; Woodhead

528 1998; Beverton et al. 2004; Reznick et al. 2006; Hendry et al. 2004; Reznick et al. 2004;

529 Morbey et al. 2005; Carlson et al. 2007; Terzibasi Tozzini et al. 2013; Uriarte et al.

530 2016; Benoît et al. 2018), taking senescence into consideration in fisheries stock

531 assessments could improve the accuracy of stock assessment and success in

532 management. As described by Le Bris et al. (2015), fisheries models that predict

533 population dynamics often assume that individual fecundity increases with the

534 increasing size of fish. These models are particularly sensitive to variations in the

535 fecundity-mass relationship (Le Bris et al. 2015). Therefore, for species that undergo

536 senescence, estimates of fecundity that ignore senescence may prove to be incorrect.

537 As discussed above, the smaller and younger fish may have an important role in

538 population recovery. 
539 Similarly, due to lack of age-specific natural mortality data, typical fisheries models assume a constant rate of natural mortality regardless of the age and size of the fish, or

541 a rate of natural mortality that scales with body size raised to a negative power

542 (summarised in Gislason et al., 2010), thereby assuming a decreased rate of natural 543 mortality as the individual grows and ages. For species experiencing senescence,

544 ignoring changes in natural mortality with age could lead to unrealistically low mortality 545 estimates. Additionally, it could mask the importance of young individuals in population 546 recovery, hindering our management efforts further. Recruitment and natural mortality 547 are the basic building blocks of stock assessment, and therefore ignoring the ways that senescence can change them could lead to biased estimates of fish population sizes.

549 Inaccuracies in stock assessment models, whether related to reproductive capacity or 550 mortality rates, may risk the sustainability of fishing.

551 Importantly, the practice of conserving old and large individuals (Birkeland and Dayton 552 2005), may not be sufficient, and could even be harmful if senescence is indeed widely 553 present in fishes. While old and large individuals have important functions in the wider 554 ecosystem as predators (Petchey et al. 2008), trainers of young ones in migration and 555 feeding (Petitgas et al. 2010), and in contributing to the gene pool (Uusi-Heikkilä et al. 556 2015), their role in maintaining population resiliency through recruitment may not be as 557 pivotal as is thought. On the one hand, this may be because if senescence is widely 558 present in fishes, then relying on large individuals could be misleading if their natural 559 mortality is higher than estimated, and their reproductive output is lower than estimated. 560 On the other hand, it may be because we are under-estimating the role of smaller and 561 younger individuals and their reproductive capacity. Early life reproduction may be an 
562 important contributor to population resiliency and recovery, perhaps more so than late 563 life reproduction.

564 Senescence can mask changes in life-history responses to fishing. As demonstrated in 565 the present study, the presence or absence of senescence affects how the population 566 responds to different fishing selections regimes: while trawling reduced the asymptotic 567 length of non-senescent population more, gillnetting reduced the asymptotic length of 568 the senescent population more. Depending on the fishing method in question, the 569 magnitude of change in life-history characters may be higher or lower than anticipated if 570 senescence is present. As a result, the population level response will change too.

571 Failure to consider senescence as a fish life-history trait with trade-offs and population

572 level consequences will hinder our progress in understanding fish population resiliency.

573

574

575

576

577

578

579

580

581 


\section{Declarations}

583 The authors thank Markku Raatikainen for vendace age determination. This work was 584 supported by funding from the Emil Aaltonen Foundation (PAA), the Academy of 585 Finland grant no. 317495 (AK), and grant no. 325107 (SUH), Discovery Grant from the

586 National Sciences and Engineering Research Council of Canada NSERC (AK), the 587 European Research Council through COMPLEX-FISH 770884 (AK), the Finnish 588 Cultural Foundation (SUH). The authors also thank the Centre for Development, 589 Transport and the Environment for long-term financial support for vendace research in 590 Lake Puulavesi. The authors declare no conflicts of interest. The present study reflects 591 only the authors' view and the European Research Council is not responsible for any 592 use that may be made of the information it contains. 


\section{References}

613 Abrams PA, Rowe L (1996) The effects of predation on the age and size of maturity of 614 prey. Evolution (N Y) 50:1052-1061

615 Ahti PA, Kuparinen A, Uusi-heikkilä S (2020) Size does matter — the eco-evolutionary 616 effects of changing body size in fish. Environ Rev 14:1-14

617 Andersen KH, Beyer JE (2015) Size structure, not metabolic scaling rules, determines

618 fisheries reference points. Fish Fish 16:1-22. https://doi.org/10.1111/faf.12042

619 Bailey KM (2011) An Empty Donut Hole: The Great Collapse of a North American 620 Fishery. Ecol Soc 16:. https://doi.org/10.5751/ES-04124-160228 
621 Barneche DR, Robertson DR, White CR, Marshall DJ (2018) Fish reproductive-energy output increases disproportionately with body size. Science (80- ) 360:642-645

623 Benoît HP, Swain DP, Hutchings JA, et al (2018) Evidence for reproductive senescence 624 625 626

641 Charnov EL, Gislason H, Pope JG (2013) Evolutionary assembly rules for fish life 
Comfort A (1960) The effect of age on growth-resumption in fish (Lebistes) checked by food restriction. Gerontoliga 4:177-186

645 646

647

648

649

650

651

652

653

654

655

656

657

658

659

660

661

662

Comfort A (1963) Effect of delayed and resumed growth on the longevity of a fish (Lebistes reticulatus, Peters) in captivity. Gerontologia 8:150-155

Dulvy NK, Sadovy Y, Reynolds JD (2003a) Extinction vulnerability in marine populations

Dulvy NK, Yvonne S, Reynolds JD (2003b) Extinction vulnerability in marine populations. Fish Fish 4:25-64. https://doi.org/10.1046/j.1467-2979.2003.00105.x

Enberg K, Jørgensen C, Mangel M (2010) Fishing-induced evolution and changing reproductive ecology of fish: the evolution of steepness. Can J Fish Aquat Sci 67:1708-1719. https://doi.org/10.1139/F10-090

Gerking SD (1957) Evidence of aging in natural populations of fishes. Gerontologia $1: 287-305$

Gislason H, Daan N, Rice JC, Pope JG (2010) Size, growth, temperature and the natural mortality of marine fish. Fish Fish 11:149-158.

https://doi.org/10.1111/j.1467-2979.2009.00350.x

Graves JL, Mueller LD (1993) Population density effects on longevity. Genetica 91:99109. https://doi.org/10.1007/BF01435991

Heino M, Beatriz DP, Dieckmann U (2015) Fisheries-Induced Evolution. Annu Rev Ecol Evol Syst 46:461-480. https://doi.org/10.1146/annurev-ecolsys-112414-054339

Heino M, Kaitala V (1999) Evolution of resource allocation between growth and 
reproduction in animals with indeterminate growth. J Evol Biol 12:423-429. https://doi.org/10.1046/j.1420-9101.1999.00044.x

Hendry AP, Morbey YE, Berg OK, Wenburg JK (2004) Adaptive variation in senescence: reproductive lifespan in a wild salmon population. Proc R Soc B 259266. https://doi.org/10.1098/rspb.2003.2600

Hunter A, Speirs DC, Heath MR (2015) Fishery-induced changes to age and length dependent maturation schedules of three demersal fish species in the Firth of Clyde. Fish Res 170:14-23. https://doi.org/10.1016/j.fishres.2015.05.004

Hutchings JA, Reynolds JD (2004) Marine fish population collapses: Consequences for recovery and extinction risk. Bioscience 54:297-309. https://doi.org/10.1641/00063568(2004)054

Jackson JBC (2008) Ecological extinction and evolution in the brave new ocean. Proc Natl Acad Sci 105:11458-11465. https://doi.org/10.1073/pnas.0802812105

Jensen AL (1996) Beverton and Holt life history invariants result from optimal trade-off of reproduction and survival. Can J Fish Aquat Sci 53:820-822. https://doi.org/10.1139/f95-233

Jensen AL (1998) Simulation of relations among fish life history parameters with a bioenergetics-based population model. Can J Fish Aquat Sci 55:353-357

Karjalainen J, Urpanen O, Keskinen T, et al (2016) Phenotypic plasticity in growth and fecundity induced by strong population fluctuations affects reproductive traits of female fish. Ecol Evol 6:779-790. https://doi.org/10.1002/ece3.1936 
684 Kirkwood TBL, Rose MR (1991) Evolution of senescence: late survival sacrificed for 685 reproduction. Philos Trans - R Soc London, B 332:15-24. https://doi.org/10.1098/rstb.1991.0028

687 Kirkwood TBL, Shanley DP (2010) The connections between general and reproductive 688 689 690 691 692 693 694 695 696 697 698 699 700

701 Lemaître JF, Berger V, Bonenfant C, et al (2015) Early-late life trade-offs and the 702

703 Kuparinen A, Hardie DC, Hutchings JA (2011) Evolutionary and ecological feedbacks of the survival cost of reproduction. Evol Appl 5:245-255. https://doi.org/10.1111/j.1752-4571.2011.00215.x

Kuparinen A, Kuikka S, Merilä J (2009) Estimating fisheries-induced selection: Traditional gear selectivity research meets fisheries-induced evolution. Evol Appl 2:234-243. https://doi.org/10.1111/j.1752-4571.2009.00070.x

Le Bris A, Pershing AJ, Hernandez CM, et al (2015) Modelling the effects of variation in reproductive traits on fish population resilience. ICES J Mar Sci 72:2590-2599

Lemaitre J-F, Gaillard J, Pemberton JM, et al (2014) Early life expenditure in sexual competition is associated with increased reproductive senescence in male red deer. Proc R Soc B Biol Sci

02 evolution of ageing in the wild. Proc R Soc B Biol Sci 282:. https://doi.org/10.1098/rspb.2015.0209

704 Lester NP, Shuter BJ, Abrams PA (2004) Interpreting the von Bertalanffy model of 
724

725

somatic growth in fishes: the cost of reproduction. Proc R Soc B Biol Sci 271:16251631. https://doi.org/10.1098/rspb.2004.2778

Maklakov AA, Chapman T (2019) Evolution of ageing as a tangle of trade-offs: energy versus function. Proc R Soc B Biol Sci 286:20191604.

https://doi.org/10.1098/rspb.2019.1604

Marjomäki TJ (2005) Evaluation of different harvest strategies for a vendace population with highly variable recruitment: A simulation approach. Boreal Environ Res 10:255-273

Marjomäki TJ, Huolila M (2001) Long-term dynamics of pelagic fish density and vendace (Coregonus albula (L.)) stocks in four zones of a lake differing in trawling intensity. Ecol Freshw Fish 10:65-74. https://doi.org/10.1034/j.16000633.2001.100201.x

Marjomäki TJ, Urpanen O, Karjalainen J (2014) Two-year cyclicity in recruitment of a fish population is driven by an inter-stage effect. Popul Ecol 56:513-526. https://doi.org/10.1007/s10144-014-0439-0

Merino G, Barange M, Blanchard JL, et al (2012) Can marine fisheries and aquaculture meet fish demand from a growing human population in a changing climate? Glob Environ Chang 22:795-806. https://doi.org/10.1016/j.gloenvcha.2012.03.003

Monaghan P, Charmantier A, Nussey DH, Ricklefs RE (2008) The evolutionary ecology of senescence. Funct Ecol 22:371-378. https://doi.org/10.1111/j.13652435.2008.01418.x 
726 Monastyrsky GN (1930) O metodakh opredeleniya lineinogo rosta po cheshue ryb

727

728

729

730

731

732

733

734

735

736

737

738

739

740

741

742

743

744

745

746

(methods of determining the growth of fish in length by their scales). Tr Nauch Ryb Khozy 5:5-44

Morbey YE, Brassil CE, Hendry AP (2005) Rapid Senescence in Pacific Salmon. Am Nat 166:556-568. https://doi.org/10.1086/491720

Mousseau TA, Roff DA (1987) Natural selection and the heritability of fitness components. Heredity (Edinb) 59:181-197. https://doi.org/10.1038/hdy.1987.113

Myers RA, Barrowman JAHNJ (1997) Why do Fish Stocks Collapse? The Example of Cod in Atlantic Canada. Ecol Appl 7:91-106

Nussey DH, Froy H, Lemaitre JF, et al (2013) Senescence in natural populations of animals: Widespread evidence and its implications for bio-gerontology. Ageing Res Rev 12:214-225. https://doi.org/10.1016/j.arr.2012.07.004

Olsen EM, Carlson SM, Gjøsæter J, Stenseth NC (2009) Nine decades of decreasing phenotypic variability in Atlantic cod. Ecol Lett 12:622-631.

https://doi.org/10.1111/j.1461-0248.2009.01311.x

Patnaik BK, Mahapatro N, Jena BS (1994) Ageing in fishes. Gerontology 40:113-132. https://doi.org/10.1159/000213582

Pedersen EJ, Link H, Thompson PL, et al (2017) Signatures of the collapse and incipient recovery of an overexploited marine ecosystem. R Soc Open Sci 4:170215. https://doi.org/10.1098/rsos.170215

Perissi I, Bardi U, Bardi U, Lavacchi A (2017) Dynamic patterns of overexploitation in 
fisheries. Ecol Modell 359:285-292.

https://doi.org/10.1016/j.ecolmodel.2017.06.009

Petchey OL, Beckerman AP, Riede JO, Warren PH (2008) Size, foraging, and food web structure. Proc Natl Acad Sci 105:4191-4196. https://doi.org/10.1073/pnas.0710672105

Petitgas P, Secor DH, Mcquinn I, et al (2010) Stock collapses and their recovery: mechanisms that establish and maintain life-cycle closure in space and time. ICES J Mar Sci 67:1841-1848

Quince C, Abrams PA, Shuter BJ, Lester NP (2008) Biphasic growth in fish I: Theoretical foundations. J Theor Biol 254:197-206. https://doi.org/10.1016/j.jtbi.2008.05.029

Reznick D, Bryant M, Holmes D (2006) The evolution of senescence and postreproductive lifespan in guppies (Poecilia reticulata). PLoS Biol 4:0136-0143. https://doi.org/10.1371/journal.pbio.0040007

Reznick D, Ghalambor C, Nunney L (2002) The evolution of senescence in fish. Mech Ageing Dev 123:773-789. https://doi.org/10.1016/S0047-6374(01)00423-7

Reznick DN, Bryant MJ, Roff D, et al (2004) Effect of extrinsic mortality on the evolution of senescence in guppies. Nature 431:1095-1099. https://doi.org/10.1038/nature03042.Published Ricker WE (1975) Computation and interpretation of biological statistics of fish populations. Bull Fish Res Board Canada 401. https://doi.org/10.1038/108070b0 
Rochet M-J (1998) Short-term effects of fishing on life history traits of fishes. ICES J Mar Sci 55:371-391

Rougier T, Lambert P, Drouineau H, et al (2012) Collapse of allis shad, Alosa alosa, in the Gironde system (southwest France): environmental change, fishing mortality, or Allee effect? ICES J Mar Sci 69:1802-1811

Selman C, Blount JD, Nussey DH, Speakman JR (2012) Oxidative damage, ageing, and life-history evolution: Where now? Trends Ecol Evol 27:570-577. https://doi.org/10.1016/j.tree.2012.06.006

Terzibasi Tozzini E, Dorn A, Ng'Oma E, et al (2013) Parallel evolution of senescence in annual fishes in response to extrinsic mortality. BMC Evol Biol 13:. https://doi.org/10.1186/1471-2148-13-77

Uriarte A, Ibaibarriaga L, Pawlowski L, et al (2016) Assessing natural mortality of Bay of Biscay anchovy from. 234:216-234

Uusi-Heikkilä S, Whiteley AR, Kuparinen A, et al (2015) The evolutionary legacy of sizeselective harvesting extends from genes to populations. Evol Appl 8:597-620. https://doi.org/10.1111/eva.12268

von Bertalanffy L (1949) Problems of organic growth. Nature 163:156-158

von Bertalanffy L (1938) A quantitative theory of organic growth (Inquiries on growth laws. II). Hum Biol 10:181-213

Williams GC (1957) Pleiotropy, Natural Selection, and the Evolution of Senescence. Evolution (N Y) 11:398-411. https://doi.org/10.2307/2406060 
789

790

791

792

793

794

795

796

797

798

799

800

801

802

803

804

805

806

807

808

809

Woodhead AD (1998) Aging, the fishy side: An appreciation of Alex Comfort's studies. Experiemntal Gerontol 33:39-51

Woodhead AD, Ellett S (1969a) Aspects of ageing in the guppy, Lebistes reticulatus (Peters)-IV The ovary. Exp Gerontol 4:197-205

Woodhead AD, Ellett S (1969b) Endocrine aspects of ageing in the guppy, Lebistes reticulatus (Peters) III. The testis. Exp Gerontol 4:17-25

Woodhead AD, Ellett S (1966) Endocrine aspects of ageing in the guppy, Lebistes reticulatus (Peters) I. The thyroid gland. Exp Gerontol 1:315-330

Woodhead AD, Ellett S (1967) Endocrine aspects of ageing in the guppy, Lebistes reticulatus (Peters) II. The interrenal gland. Exp Gerontol 2:159-171

Zhang Y, Hood WR (2016) Current versus future reproduction and longevity: a reevaluation of predictions and mechanisms. J Exp Biol 219:3177-3189. https://doi.org/10.1242/jeb.132183

Zimmermann F, Jørgensen C (2015) Bioeconomic consequences of fishing-induced evolution: a model predicts limited impact on net present value. Can J Fish Aquat Sci 72:612-624. https://doi.org/10.1139/cjfas-2014-0006

R Core Team (2018). R: A language and environment for statistical computing. $R$ Foundation for Statistical Computing, Vienna, Austria. URL https://www.R-project.org/.

Roff, D. A. 2002. Life History Evolution. Sinauer, Sunderland, MA. 
Kirkwood. T.B.L 1977. Evolution of ageing. Nature 270: 301-304.

811 Medawar, P.B., 1952. An Unsolved Problem of Biology. Lewis, London.

812 R. J. H. Beverton, S. J. Holt, On the Dynamics of Exploited Fish Populations (Fishery 813 Investigations Series II, Her Majesty's Stationery Office, London, 1957), vol. 19.

814 D. A. Roff, An allocation model of growth and reproduction in fish. Can. J. Fish. Aquat. 815 Sci.

816 40, 1395-1404 (1983). doi:10.1139/f83-161

817 Marjomäki and Huolila M. (1994): Yield, stock fluctuation, total mortality and growth of 818 Lake Puulavesi vendace (Coregonus ølbula (L.)) in 1984-1992. - Jyväskylän yliopiston 819 biologian laitoksen tiedonantoja 68: 37 - 66. [Finnish, Engl. summary]

820 Carey, J.R., Judge, D.S., 2000. Longevity Records: Lifespans of Mammals, Birds, 821 Amphibians, Reptiles, and Fish. Odense University Press, Odense, Denmark.

822 Viljanen M. 1986: Biology, propagation, exploitation and management of vendace 823 (Coregonus albula L.) ín Finland. -Arch. hydrobiol. Beih. Ergebn. Limnol. 22: 73-97. 824 Jurvelius, J., 1991. Distribution and density of pelagic fish stocks, especially vendace 825 (Coregonus albula (L.)), monitored by hydroacoustics in shallow and deep southern 826 boreal lakes. Finnish Fish. Res. 12: 45-63.

827 Järvi, T. H., 1920. Die kleine Maräne, Coregonus albula L., in Keitelesee. Annales 828 Acad. scient. Fennicae. Ser. A. Vol. 14 


\section{$833 \quad$ Figure legends}

834 Fig 1. A schematic diagram of the modelling approach. (A) The fish length-at-age was 835 back-calculated from fish scales. These data were then used to fit the von Bertalanffy 836 growth equation to model the $L_{\infty}$. The $L_{\infty}$ was set to be an evolving trait so that the 837 genotype coding the $L_{\infty}$ of each individual was described by 10 diploid loci with two 838 alleles in each, one from the mother, one from the father. (B) The length-weight 839 relationship was specifically calculated for $C$. albula from Lake Puulavesi. Using this 840 length-weight relationship and published empirical data on egg numbers and female 841 weights (Karjalainen et al. 2016), we fitted a linear model for the fecundity-weight 842 relationship, so that as the fish body size increases, so does the egg production. (C) 843 The probability of a fertilised egg to hatch and the juvenile to survive until 2 years of age 844 was set to $(P=0.002)$ and the sex of the juveniles was drawn from a Bernoulli trial with 845 a probability of 0.5 . (D) The population component describes density dependency so 846 that at $75 \%$ of the population carrying capacity, the individual growth is reduced to $50 \%$ 847 of that predicted by the individual's vB growth curve. Additionally, egg production was set to be density dependent so that the closer the population was to its carrying capacity, the fewer eggs were produced. (F) Reproductive senescence and actuarial senescence are the independent variables in the model. The reproductive senescence

851 was modelled by multiplying the linear model for fecundity by the fecundity factor based 852 on the gonadosomatic index (GSI) for the year class in question. When no reproductive 853 senescence was modelled, only the linear model for fecundity was used. Actuarial 854 senescence was modelled by increasing the rate of natural mortality each year, as 855 opposed to keeping natural mortality rate constant throughout lifetime as in the scenario 
856 with no actuarial senescence. (F) Equipped with the above characters, the populations

857 were then allowed to live for 500 years and traced at annual time steps. The first 200

858 years the populations lived in pristine conditions, then the populations were fished either

859 by trawling or gillnetting for 100 years, and finally the populations were allowed to 860 recover for 200 years.

861 Fig 2. The mean of the asymptotic length $(\mathrm{cm})$ of fish over 500 years (first hundred 862 years not shown). The dashed lines denote the start (year 200) and end (year 300) of 863 fishing. The solid lines denote the asymptotic length mean in hundred replicated 864 scenarios. The black line describes a scenario with reproductive and actuarial 865 senescence, red line a scenario with actuarial senescence only, blue line a scenario 866 with no senescence, and green line a scenario with reproductive senescence only.

Fig. 3. Results for the (a, b) asymptotic length (cm), (c, d) biomass (units), and (e, f) the 869 number $(\mathrm{N})$ of fish. In $\mathbf{a}, \mathbf{c}$, and $\mathbf{d}$ the fishing simulated trawling (logistic selection) and in $\mathbf{b}, \mathbf{d}$ and $\mathbf{f}$ the fishing simulated gillnetting (dome-shaped selection). The solid black

871 lines represent hundred independent replicates of the scenario with senescence, the 872 red lines represent hundred independent replicates of the scenario with no senescence 873 present. The dashed lines denote the start (year 200) and end (year 300) of fishing.

875 Fig. 4. The relative percentage change (a, b) asymptotic length $(\mathrm{cm}),(\mathbf{c}, \mathbf{d})$ biomass

876 (units), and $(\mathbf{e}, \mathbf{f})$ the number $(\mathrm{N})$ of fish. In $\mathbf{a}, \mathbf{C}$, and $\mathbf{d}$ the fishing simulated trawling 877 (logistic selection) and in $\mathbf{b}, \mathbf{d}$ and $\mathbf{f}$ the fishing simulated gillnetting (dome-shaped 
878 selection). The change has been scaled so that years $1-100$ were considered as the

879 starting point and given a value of 0 . Changes in all of the parameters (asymptotic

880 length, BM, N) after that are relative changes compared to years $1-100$. The black

881 lines denote a scenario with senescence, the red lines denote a scenario without

882 senescence. The dashed lines denote the start (year 200) and end (year 300) of fishing.

883 Given the scale of the $\mathrm{Y}$ axis, the $95 \%$ confidence intervals are virtually invisible.

Appendix S1. The lifetime cumulative number of offspring in each age group during the

886 last ten years before fishing commences and the population is in equilibrium, and during

887 the last ten years of intensive fishing (after 90 years of constant fishing). The red

888 boxplots denote scenarios without senescence and black and white boxplots denote 889 scenarios with both actuarial and reproductive senescence present.

Appendix S2. The lifetime cumulative number of offspring in each age group during the

892 last ten years before fishing commences and the population is in equilibrium, and during

893 the last ten years of intensive fishing (after 90 years of constant fishing). The green

894 boxplots denote scenarios with reproductive senescence and blue boxplots denote 895 scenarios with actuarial senescence present.

897 Appendix S3. Results for the (a) asymptotic length (cm), (b) instrinsic growth rate $k$, (c) 898 average size $(\mathrm{cm})$ at maturation, and (d) average age (years) at maturation over 899 hundred years (first hundred years not shown). The black lines represent hundred 
900 independent replicates of the scenario with senescence, the red lines represent

901 hundred independent replicates of the scenario with no senescence present. The 902 dashed lines denote the start (year 200) and end (year 300) of fishing. 


\section{Figures}

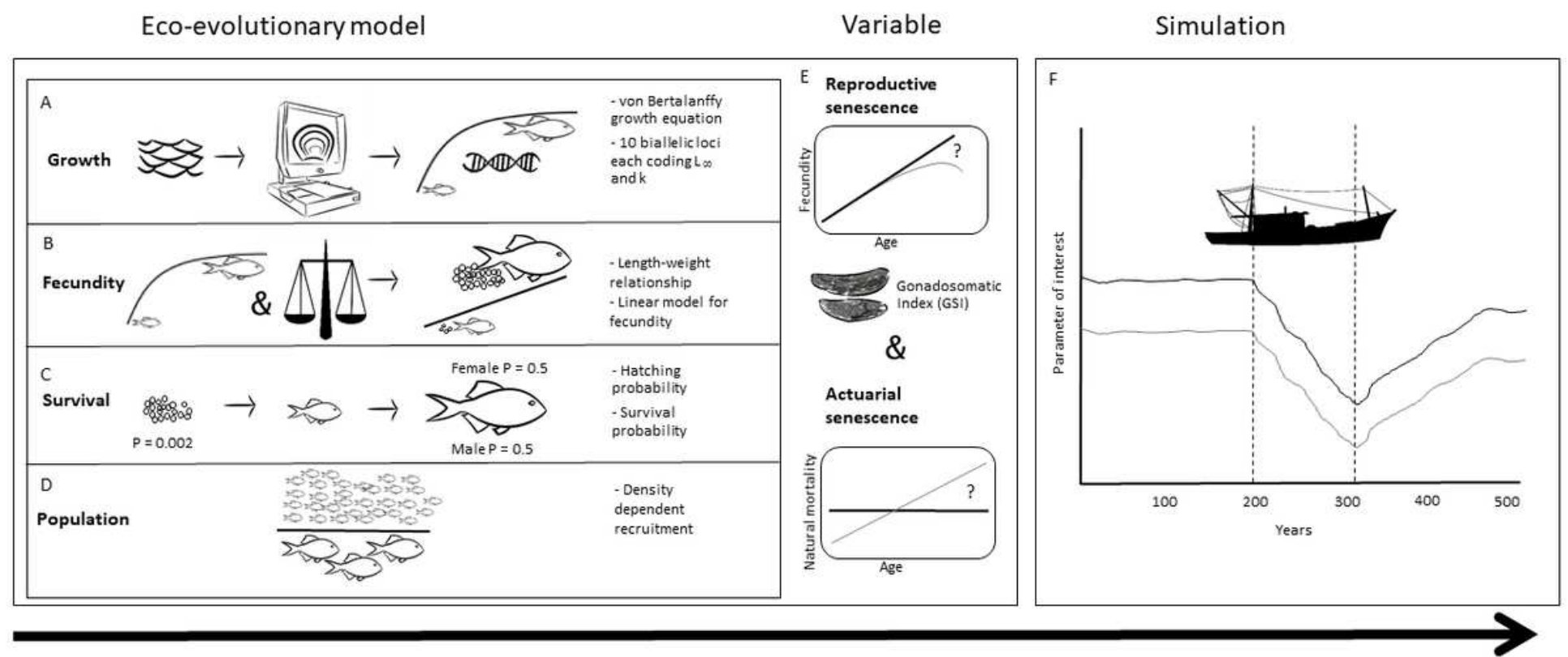

\section{Figure 1}

. A schematic diagram of the modelling approach. (A) The fish length-at-age was back-calculated from fish scales. These data were then used to fit the von Bertalanffy growth equation to model the $L_{-}{ }^{\infty}$. The $L_{-}{ }^{\infty}$ was set to be an evolving trait so that the genotype coding the $L_{-}{ }^{\infty}$ of each individual was described by 10 diploid loci with two alleles in each, one from the mother, one from the father. (B) The length-weight relationship was specifically calculated for $\mathrm{C}$. albula from Lake Puulavesi. Using this length-weight relationship and published empirical data on egg numbers and female weights (Karjalainen et al. 2016), we fitted a linear model for the fecundity-weight relationship, so that as the fish body size increases, so does the egg production. (C) The probability of a fertilised egg to hatch and the juvenile to survive until 2 years of age was set to $(P=0.002)$ and the sex of the juveniles was drawn from a Bernoulli trial with a probability of 0.5 . (D) The population component describes density dependency so that at $75 \%$ of the population carrying capacity, the individual growth is reduced to $50 \%$ of that predicted by the individual's vB growth curve. Additionally, egg production was set to be density dependent so that the closer the population was to its carrying capacity, the fewer eggs were produced. (F) Reproductive senescence and actuarial senescence are the independent variables in the model. The reproductive senescence was modelled by multiplying the linear model for fecundity by the fecundity factor based on the gonadosomatic index (GSI) for the year class in question. When no reproductive senescence was modelled, only the linear model for fecundity was used. Actuarial senescence was modelled by increasing the rate of natural mortality each year, as opposed to keeping natural mortality rate constant throughout 
lifetime as in the scenario with no actuarial senescence. (F) Equipped with the above characters, the populations were then allowed to live for 500 years and traced at annual time steps. The first 200 years the populations lived in pristine conditions, then the populations were fished either by trawling or gillnetting for 100 years, and finally the populations were allowed to recover for 200 years.

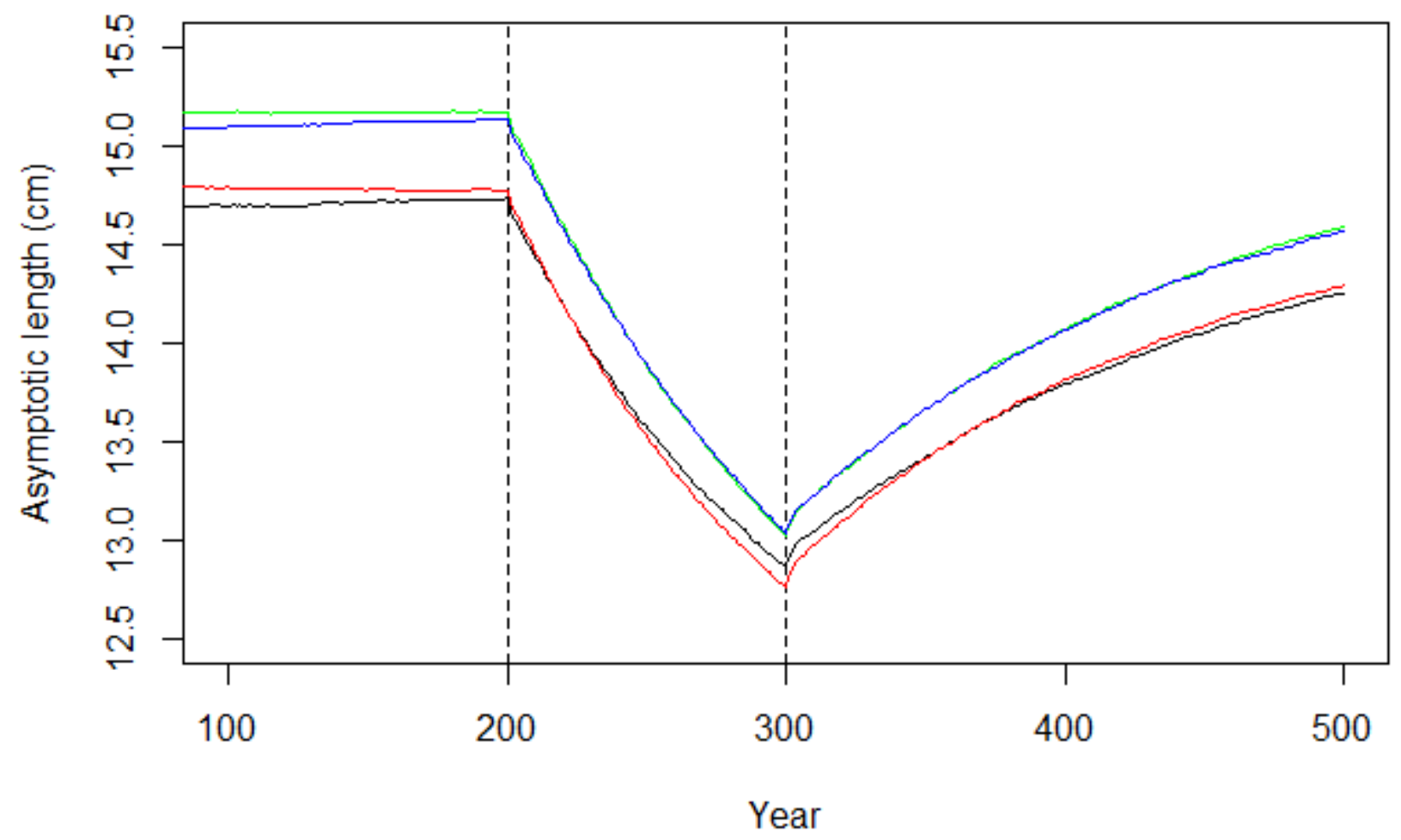

\section{Figure 2}

The mean of the asymptotic length $(\mathrm{cm})$ of fish over 500 years (first hundred years not shown). The dashed lines denote the start (year 200) and end (year 300) of fishing. The solid lines denote the asymptotic length mean in hundred replicated scenarios. The black line describes a scenario with reproductive and actuarial senescence, red line a scenario with actuarial senescence only, blue line a scenario with no senescence, and green line a scenario with reproductive senescence only. 

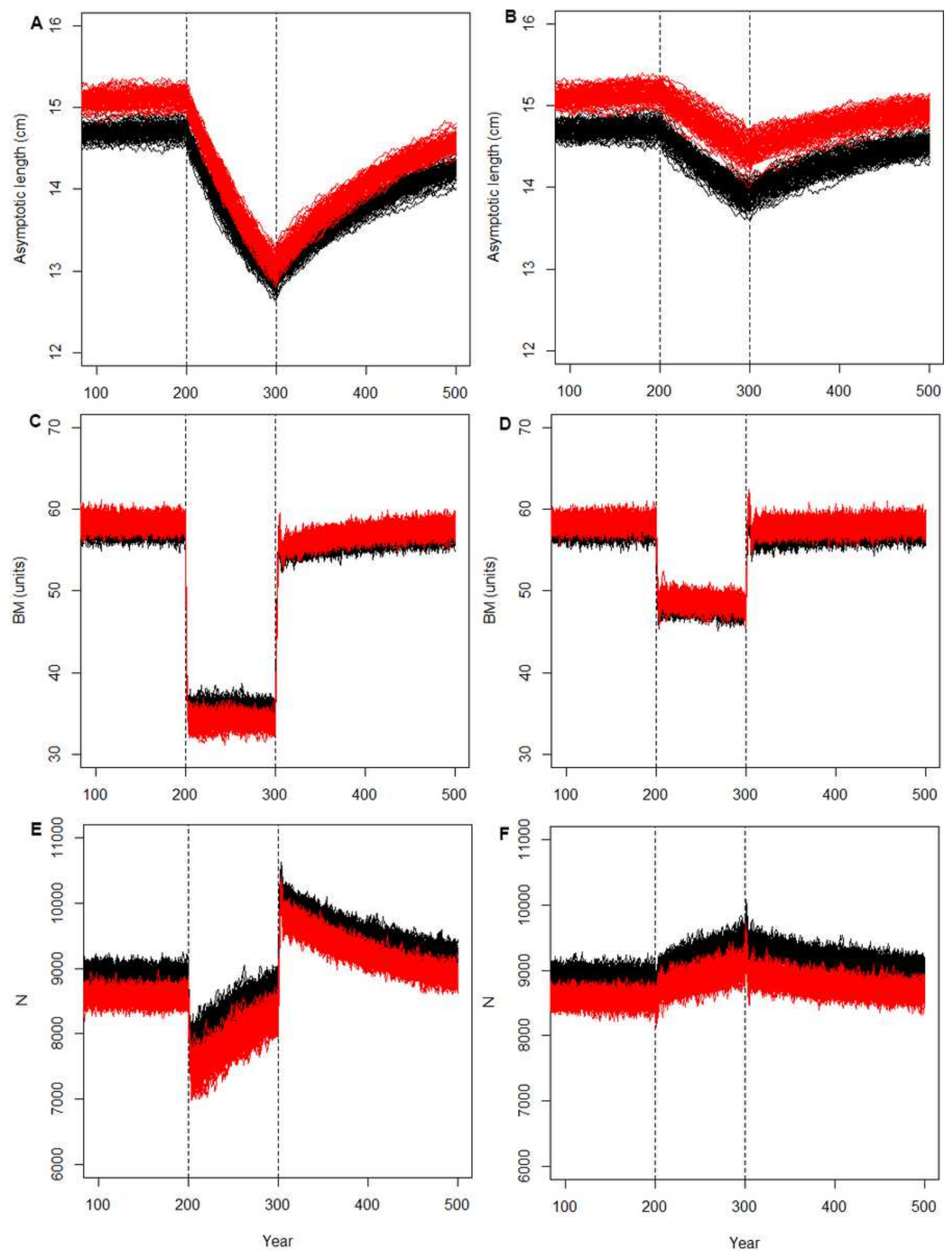

\section{Figure 3}

Results for the $(a, b)$ asymptotic length (cm), (c, d) biomass (units), and (e, f) the number (N) of fish. In a, $c$, and $d$ the fishing simulated trawling (logistic selection) and in $b, d$ and $f$ the fishing simulated gillnetting (dome-shaped selection). The solid black lines represent hundred independent replicates of the scenario with senescence, the red lines represent hundred independent replicates of the scenario with no senescence present. The dashed lines denote the start (year 200) and end (year 300) of fishing. 

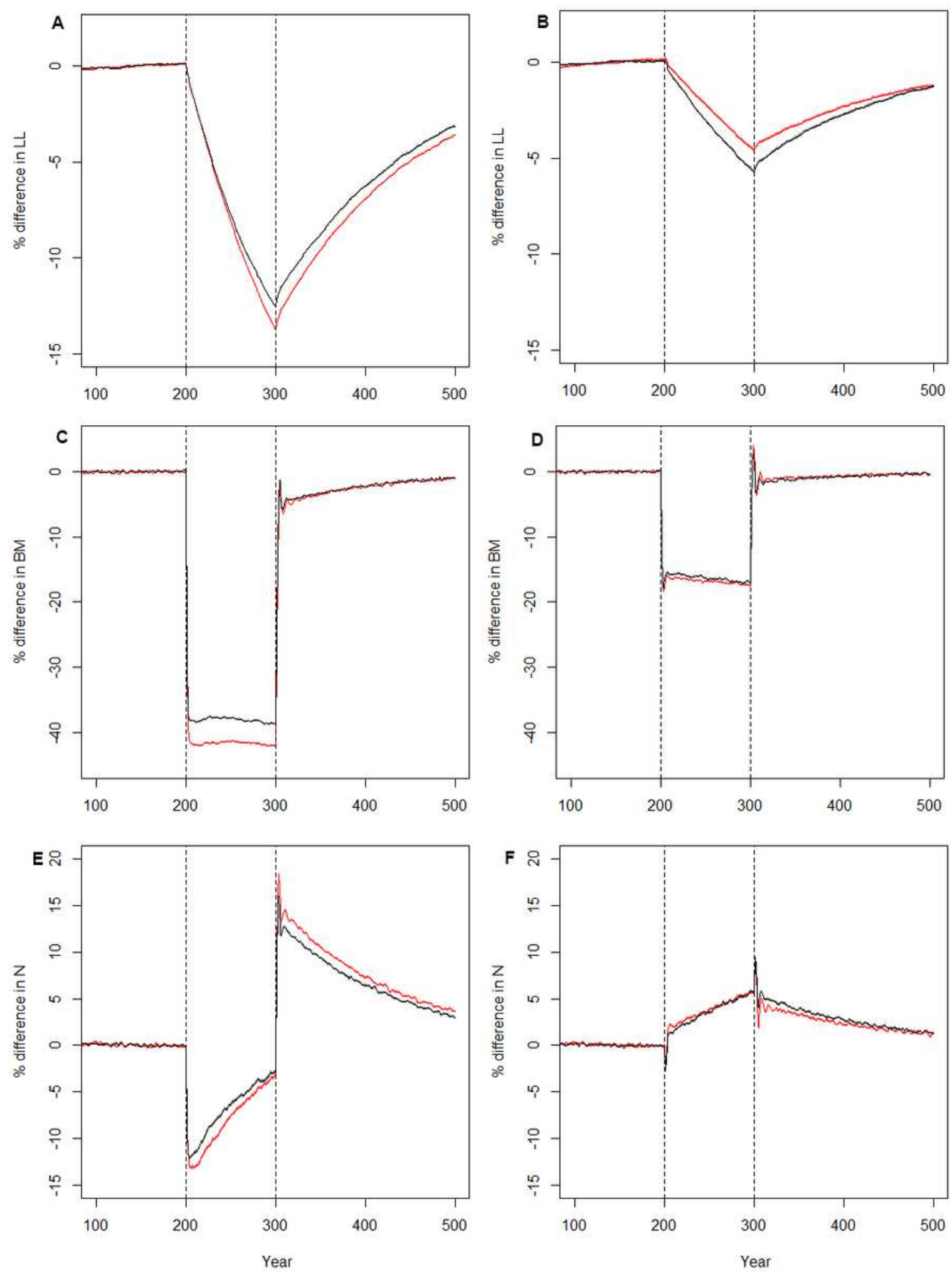

Figure 4

The relative percentage change $(a, b)$ asymptotic length $(\mathrm{cm}),(c, d)$ biomass (units), and $(e, f)$ the number $(\mathrm{N})$ of fish. In $\mathrm{a}, \mathrm{c}$, and $\mathrm{d}$ the fishing simulated trawling (logistic selection) and in $\mathrm{b}, \mathrm{d}$ and $\mathrm{f}$ the fishing simulated gillnetting (dome-shaped selection). The change has been scaled so that years $1-100$ were considered as the starting point and given a value of 0 . Changes in all of the parameters (asymptotic length, BM, N) after that are relative changes compared to years $1-100$. The black lines denote a 
scenario with senescence, the red lines denote a scenario without senescence. The dashed lines denote the start (year 200) and end (year 300) of fishing. Given the scale of the $Y$ axis, the $95 \%$ confidence intervals are virtually invisible.

\section{Supplementary Files}

This is a list of supplementary files associated with this preprint. Click to download.

- S1.png

- S2.png

- S3.png 